\title{
The Analytical Stormwater Management Model (ASWMM)
}

\author{
Yiping Guo and Barry J. Adams
}

This chapter outlines the methodology and procedures used in the development and verification of the Analytical Stormwater Management Model (ASWMM). ASWMM is a collection of analytical expressions relating the runoff characteristics and stormwater detention pond performance measures of urban catchments directly to the input rainfall statistics and system parameters. These analytical expressions are derived from the simplified mathematical representation of the hydrologic and hydraulic processes involved. The input rainfall event characteristics are treated as exponentially distributed random variables. Preliminary testing and verification indicate that the ASWMM results are generally in close agreement with those generated from the U.S. EPA SWMM model. The use of ASWMM is therefore proposed for the planning and design of urban stormwater management facilities.

\subsection{Introduction}

The Stormwater Management Model (SWMM) (Huber and Dickinson, 1988) has been widely used in the planning and design of stormwater management facilities for urban areas. Continuous simulation using SWMM or other numerical

Guo, Y. and B.J. Adams. 1999. "The Analytical Stormwater Management Model (ASWMM)." Journal of Water Management Modeling R204-19. doi: 10.14796/JWMM.R204-19.

(C) CHI 1999 www.chijournal.org ISSN: 2292-6062 (Formerly in New Applications in Modeling Urban Water Systems. ISBN: 0-9697422-9-0) 
hydrologic models is performed to predict the volumes and peak discharge rates of runoff from urban catchments associated with certain return periods, and the performance of stormwater quantity and quality control facilities.

The objective of this chapter is to outline the development and testing of a set of mathematical expressions which can be used for the determination of the runoff event volume and peak discharge rate from urban catchments associated with certain return periods, and the runoff quantity and quality control performance provided by a detention pond servicing an urban catchment. These expressions, collectively referred to as the Analytical Stormwater Management Model, or ASWMM, relate statistical urban drainage system performance measures directly to meteorological parameters, system properties and design variables. Compared with numerical hydrologic models, ASWMM is computationally more efficient and can be used as an alternative to numerical hydrologic models in the planning and design of stormwater management facilities for urban areas.

The approach taken for the development of ASWMM can be briefly summarized as follows. Firstly, statistical analyses of long-term rainfall records are performed, leading to the determination of the probability density functions (pdfs) of rainfall event characteristics. Secondly, the hydrologic and hydraulic processes taking place on an urban catchment are mathematically represented on an event-by-event basis, establishing the functional relationship between the input rainfall characteristics and the output runoff characteristics. Thirdly, the pdfs of runoff characteristics are derived from those of the input rainfall characteristics and the functional relationships between the input and output variables. The derivation process for the determination of the desired pdfs follows the principle of derived probability distribution theory (Benjamin and Cornell, 1970). Details of the development and verification processes, and some of the lengthy analytical solutions are contained in Guo (1998). This chapter serves as an introduction to, and an outline of, the proposed methodology.

\subsection{Statistical Analysis of Rainfall Data}

Urban catchments are often small in size, ranging from several hectares to a few hundred hectares. It is assumed that rainfall on catchments of such size is adequately described by a representative point rainfall. In the statistical analysis of historical rainfall records, a continuous rainfall series is first divided into discrete rainfall events. The criterion for distinguishing between events is a minimum time period without rainfall (termed the minimum interevent time definition - IETD). Rainfall periods separated by a time interval longer than the IETD are considered to be separate rainfall events. Once this distinction is made, a point rainfall series may be divided into discrete events and the characteristics of these events may be statistically analyzed. 
The choice of the IETD is governed by the intended application. The results of this research may be applied to urban catchments with a response time (such as the time of concentration) of the order of half an hour to two or three hours. To ensure a one-to-one correspondence between rainfall and runoff events on these catchments, the IETD for rainfall event separation should be greater than the catchment response time. On the other hand, if the IETD is too long, consecutive rainfall events are considered to belong to the same event. Thus, an IETD of about six hours may be considered appropriate for the analysis of typical urban catchments. Details on meteorological data analysis for urban drainage system design and the proper choice of the IETD can be found in Adams et al. (1986), Eagleson (1972), Fraser (1982), Howard (1976), and Restrepo-Posada and Eagleson (1982).

Each rainfall event is characterized by its rainfall volume (v), rainfall duration ( $t$ ), and interevent time (b). The historical rainfall record can then be viewed as comprising a time series for each of the above characteristics which individually may be submitted to a frequency analysis. Histograms of the time series are prepared and probability density functions are fitted to the histograms. An average annual number of storm events can also be obtained from these statistical calculations. It has been found that exponential pdfs often fit such histograms satisfactorily (Eagleson, 1972; Howard, 1976; Adams et al., 1984, 1986). For the development of ASWMM, the exponential distributions for rainfall characteristics as given in Table 19.1 are considered appropriate. In Table 19.1, $\bar{v}, \bar{t}$, and $\bar{b}$ are the average event volume, average event duration, and average interevent time of the rainfall record, respectively. As an example, the 33-year historical rainfall record of Pearson International Airport in Toronto, Canada was analyzed, and the resulting statistics are included in Table 19.1.

Table 19.1 Probability density functions of rainfall characteristics and rainfall statistics for Toronto, Canada (IETD $=6 \mathrm{~h}$ ).

\begin{tabular}{lccc}
\hline Rainfall Characteristic & Exponential pdf & $\begin{array}{c}\text { Distribution } \\
\text { Parameter }\end{array}$ & $\begin{array}{c}\text { Toronto } \\
\text { Statistics }\end{array}$ \\
\hline Volume, $v(\mathrm{~mm})$ & $\mathrm{f}_{\mathrm{V}}(\mathrm{v})=\zeta \exp (-\zeta \mathrm{v})$ & $\zeta=\frac{1}{\bar{v}}$ & $\overline{\mathrm{v}}=9.43 \mathrm{~mm}$ \\
\hline Duration, $t(\mathrm{~h})$ & $\mathrm{f}_{\mathrm{T}}(\mathrm{t})=\lambda \exp (-\lambda \mathrm{t})$ & $\lambda=\frac{1}{\overline{\mathrm{t}}}$ & $\overline{\mathrm{t}}=7.73 \mathrm{hours}$ \\
\hline Interevent Time, $b(\mathrm{~h})$ & $\mathrm{f}_{\mathrm{B}}(\mathrm{b})=\psi \exp (-\psi \mathrm{b})$ & $\psi=\frac{1}{\overline{\mathrm{b}}}$ & $\overline{\mathrm{b}}=103.1 \mathrm{hours}$ \\
\hline & Average Annual Number of Rainfall Events, $\theta$ & 57.2 \\
\hline & Average Annual Rainfall Volume & $550 \mathrm{~mm}$ \\
\hline
\end{tabular}




\subsection{Rainfall-Runoff Transformation}

The rainfall-runoff transformation discussed in this section establishes the relationships between the input rainfall event characteristics and the output runoff event characteristics. Once these functional relationships are established, the probability distributions of those runoff characteristics, which are of interest in planning and design, can be established using derived probability distribution theory.

A runoff event as considered here is characterized by runoff event volume, runoff event duration and peak discharge rate. The calculated runoff event volume is the difference between the volume of the input rainfall event and the total volume of hydrologic losses. For the purposes of hydrologic modeling, interception and depression storage losses are often lumped together. The same approach is taken in the development of ASWMM; thus, depression storage losses hereinafter include losses due to interception. Furthermore, in the development of ASWMM, it is assumed that surface depressions are filled before any runoff occurs for each rainfall event, and that the dry period that follows is always long enough so that water accumulated in the depression storage areas is completely evaporated and surface depressions are fully available at the beginning of each rainfall event.

The total infiltration losses within a runoff event are considered to be the combination of two parts; namely, losses due to initial wetting of the soil and losses as a result of infiltration at a constant rate, $f_{c}$, throughout the duration of the runoff event. That is:

$$
S_{m f}=S_{i w}+f_{c} t
$$

where:

$$
\begin{aligned}
\mathrm{S}_{\mathrm{mf}}= & \text { the maximum possible infiltration loss volume during } \\
& \text { a rainfall event of duration } \mathrm{t} \text {; } \\
\mathrm{S}_{\mathrm{iw}}= & \text { the initial soil wetting infiltration volume which is } \\
& \text { assumed to be the same for all rainfall events; } \\
\mathrm{f}_{\mathrm{c}}= & \text { the ultimate infiltration capacity of the catchment soils. }
\end{aligned}
$$

It is shown in Guo (1998) that the value of $S_{i w}$ can be estimated from the infiltration parameters of the soil and meteorological parameters of the region.

Similar to many numerical hydrologic models, in calculating the total rainfall losses, the urban catchment is divided into impervious and pervious areas. For impervious areas, the infiltration loss is assumed to be zero and the input rainfall volume is totally converted to runoff volume after filling the impervious area depression storage, $\mathrm{S}_{\mathrm{di}}$, in $\mathrm{mm}$. 
For pervious areas, the input rainfall volume fills the pervious area depression storage, $S_{\mathrm{dp}}$, and infiltrates into the soil; the rainfall volume remaining after the filling of depression storage and infiltration into the soil becomes surface runoff. The units of $S_{d i}$ and $S_{d p}$ are $m m$ of water over the entire impervious area and the entire pervious area, respectively. The duration of infiltration is essentially the same as the rainfall duration, because it takes little time for runoff from the pervious surfaces to reach the impervious portions of the catchment or the sewer system. Thus, infiltration on the pervious portions of an urban catchment ceases soon after the end of the rainfall event. The maximum possible infiltration losses within the rainfall event are determined using Equation 19.1. To simplify expressions, the sum of $\mathrm{S}_{\mathrm{dp}}$ and $\mathrm{S}_{\mathrm{iw}}$ is denoted as $\mathrm{S}_{\mathrm{il}}$ hereafter, and is referred to as the pervious area initial losses.

The overall runoff generation of the urban catchment is the area-weighted combination of the runoff from the pervious and impervious portions of the catchment. In an urban catchment, $S_{d i}$ is usually less than $S_{d p}$. Therefore, if $v$ is less than $S_{d i}$, then $v$ must be less than $\left(S_{i l}+f_{c} t\right)$, since $f_{c}$ and $t$ are both positive. If the fraction of impervious area of the urban catchment is $h$ (for hardened surface fraction), then combining the runoff volumes from impervious and pervious areas of an urban catchment gives the following equation:

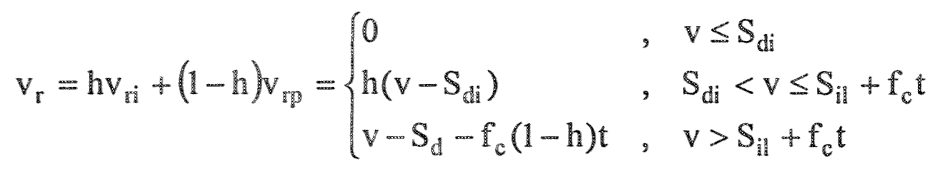

where $S_{d}=h S_{d i}-(1-h) S_{i l}$, is the area-weighted depression storage of the impervious areas and the initial losses of the pervious areas of the urban catchment. Detailed derivations of Equation 19.2 can be found in Guo (1998).

\subsection{Runoff Event Volume and Peak Discharge Rate}

Equation 19.2 describes the functional relationship between dependent random variable $v_{\mathrm{r}}$ and independent random variables $\mathrm{v}$ and $\mathrm{t}$. The probability distribution and the expected value of $v_{\mathrm{r}}$ were derived using derived probability distribution theory and this functional relationship (Guo, 1998). The derived probability distribution of $v_{r}$ is lengthy and is not suitable for hand calculations. It is not included in this chapter but can be found in Guo (1998). However, the expected value of $v_{r}$ per rainfall event has a simple form:

$$
E\left(v_{r}\right)=\frac{h}{\zeta} \exp \left(-\zeta S_{d i}\right)+\frac{\lambda(1-h)}{\zeta\left(\zeta f_{c}+\lambda\right)} \exp \left(-\zeta S_{\mathrm{il}}\right)
$$


The average annual runoff volume is simply the product of $\mathrm{E}\left(\mathrm{v}_{\mathrm{r}}\right)$ and the average annual number of rainfall events $\theta$.

The rising and recession shapes of runoff hydrographs can often be approximated by triangles. The time base of the hydrograph, or the duration of the runoff event, is derived through the use of the catchment time of concentration. The term time of concentration, denoted as $t_{\mathrm{c}}$, is defined as the time required for runoff to travel from the most remote portion of the catchment to its outlet or design point. The duration of the runoff event can then be estimated as $t+t_{c}$; i.e. the duration of the rainfall event plus the catchment time of concentration. This can be drawn from the observation that runoff at the outlet starts at the beginning of the corresponding rainfall event if the delay caused by the time needed to fill the depressions of the catchment is negligible; and that it takes time $t_{c}$ for the last drop of water falling on the most remote part of the catchment to reach the outlet.

The catchment time of concentration is treated as a constant independent of rainfall characteristics for the determination of flood frequencies. In this regard, the catchment time of concentration can be viewed as a parameter combining the effects of catchment slope, roughness, length, shape and topology. The peak discharge rate, $Q_{p}$, of a triangular hydrograph with runoff volume $v_{r}$, and time base $\left(t+t_{c}\right)$ determined from the hydrograph geometry:

$$
Q_{p}=\frac{2 v_{r}}{t+t_{c}}
$$

It is noted that the above expression for peak discharge rate is independent of the ratio of the time to peak to the time base of the hydrograph. Arguably, Equation 19.4 may provide good estimates of peak discharge rates for some runoff events, but poor estimates for other events. The overall acceptability of invoking the triangular hydrograph assumption in estimating peak discharge rate may be justified when the interest is in the determination of the exceedance probability of peak discharge rates from thousands of independent runoff events. The reasonableness of this assumption is tested when the analytically derived results are compared with those from long-term continuous simulation later in this chapter.

Using the functional relationship described in Equation 19.4, Guo (1998) derived the peak discharge rate exceedance probability per rainfall event which can be used to analytically determine the peak discharge rates associated with certain return periods. The derived peak discharge rate exceedance probability expressions are lengthy and are not suitable for hand calculations. Details of the analytical expressions can be found in Guo (1998) where they are implemented in computer spreadsheets. 


\subsection{Stormwater Quality Control Analyses}

A common scenario in urban stormwater quality control is that runoff from a contributing catchment is directed to a detention pond, and outflow from the pond is discharged to a downstream receiving water. Whenever the pond is full, inflow in excess of the maximum pond outflow rate, which corresponds to the orifice flow under the maximum head, is spilled upstream of the pond or through a spillway constructed as a part of the pond. Clearly, spills upstream of the pond receive no treatment at all, and it can be assumed that spills through the spillway of the pond receive essentially no treatment as well, because of the short detention time provided by the pond under overflow conditions.

Two performance measures, i.e. flow capture efficiency and average detention time, can be used in evaluating the long-term average pollutant removal effectiveness of stormwater detention ponds.

\subsubsection{Flow Capture Efficiency}

The flow capture efficiency, $C_{R}$, provided by a detention pond in the above scenario, is defined as the fraction of runoff volume captured by the detention pond, excluding the spill volume. In accordance with the event-based analysis method, the flow capture efficiency can be calculated as follows:

$$
C_{R}=\frac{E\left(v_{r}\right)-E(P)}{E\left(v_{r}\right)}
$$

where $E(P)$ is the expected value of the spill volume, $P$, per rainfall event, in $\mathrm{mm}$ over the catchment; and $\mathrm{E}\left(\mathrm{v}_{\mathrm{r}}\right)$ is given by Equation 19.3.

Spills from a stormwater detention pond occur due to two primary causes. On one hand, spills may occur because the pond storage volume is not sufficient to contain the runoff event volume from the catchment, even though the pond storage volume is entirely available at the beginning of the runoff event. On the other hand, spills may occur because part of the pond storage capacity is still occupied by runoff from previous events at the beginning of a runoff event. This is referred to as the carryover effect of successive storms and occurs if the outflow rate of the pond is too small for outflow to cease between successive runoff events. Differentiating spills between the two causes provides insight into the impact on spill volumes of the two pond design variables, namely, storage volume and outflow rate.

Hereafter, spills from a stormwater detention pond resulting from the small storage volume effect, neglecting the carryover effect of successive runoff events, are referred to as event spills, while spills due mainly to the carryover effect of successive runoff events are termed carryover spills. The volume of the 
event spill resulting from a rainfall event is denoted $\mathrm{P}_{\mathrm{e}}$; and the volume of the carryover spill which occurs during a rainfall event as a result of the carryover effect of previous rainfall events is denoted $\mathrm{P}_{\mathrm{c}}$.

The sum of $P_{e}$ and $P_{c}$ is the total spill volume $P$ from the input of a rainfall event to a pond which may or may not be empty at the beginning of the rainfall event because of previous events, and

$$
E(P)=E\left(P_{e}\right)+E\left(P_{c}\right)
$$

where $E\left(P_{e}\right)$ and $E\left(P_{c}\right)$ are the expected values of $P_{e}$ and $P_{c}$ per rainfall event, respectively. The annual average event spill volume, annual average carryover spill volume, and annual average spill volume can be calculated as the product of the respective expected value and the annual average number of rainfall events.

The expressions for $\mathrm{E}\left(\mathrm{P}_{\mathrm{e}}\right)$ and $\mathrm{E}\left(\mathrm{P}_{\mathrm{c}}\right)$ are derived in Guo (1998). These expressions are lengthy and are not included here. Computer spreadsheets are developed in Guo (1998) incorporating the analytical expressions for $\mathrm{E}\left(\mathrm{P}_{\mathrm{e}}\right)$ and $E\left(P_{c}\right)$. These spreadsheets can be used for the determination of flow capture efficiencies.

\subsubsection{Average Detention Time}

For each runoff event, regardless of the mixing regime in the detention pond, the volume-weighted average detention time provided by the pond is the horizontal distance between the centroids of the inflow and outflow hydrographs. This horizontal distance can be approximated by the distance between the mid-points of the time bases of the inflow and outflow hydrographs. The storage-discharge relationship of the pond may be approximated as a linear function, i.e.

$$
\mathrm{Q}=\frac{\mathrm{S}_{\mathrm{Q}}}{\mathrm{a}}
$$

where $\mathrm{S}_{\mathrm{Q}}$ (in mm over the contributing catchment) is the pond storage volume corresponding to outflow rate $\mathrm{Q}$ (in $\mathrm{mm} / \mathrm{h}$ ); and $\mathrm{a}$ (in $\mathrm{h}$ ) is the proportionality constant with a dimension of time. The storage-discharge relationships of stormwater quality control ponds are usually not exactly linear. For the estimation of average detention time, a in Equation 19.7 can be estimated from the average slope of the real storage-discharge curve.

With these approximations, it was shown (Guo, 1998) that, for any single event, the average detention time $t_{d}$ is a function of the catchment time of concentration $t_{c}$, pond design parameter $a$, and interevent time $b$. Both $t_{c}$ and $a$ are constants, while $b$ is a random variable with an exponential pdf as presented in Table 19.1. The overall volume-weighted average $t_{d}$ was derived as the expected value of $t_{d}$ and is given as follows: 


$$
E\left(t_{d}\right)=\frac{\exp \left(-\psi t_{c}\right)}{2 \psi}[1-\exp (-2 a \psi)]
$$

Equation 19.8 can be used to estimate the overall volume-weighted average detention time provided by a detention pond servicing an urban catchment. Based on Equation 19.8, it can be concluded that as a increases, the average detention time increases; while as $t_{c}$ increases, the average detention time decreases. Furthermore, Equation 19.8 shows that the overall volume-weighted average detention time is also affected by the meteorological parameter $\psi$.

\subsection{Flood Control Analyses}

Continuous probability or continuous return period criteria are often specified for the sizing of urban flood control detention facilities. These criteria require that for all storm events up to and including the most severe event, peak discharges for the developed condition with flood control in place shall not exceed peak discharges under existing conditions (Walesh, 1989). The design storm approach often represents the state-of-the-art for designing flood control detention facilities to satisfy continuous probability criteria. This involves the use of multiple design storms which are usually developed and specified by a regulatory agency of the jurisdiction.

Inherent in the design storm based approach is the assumption that the return period of the design storm is equal to the return period of the peak discharge rate from the catchment resulting from the input design storm, and furthermore, the consequent peak outflow rate from the flood control pond. It is well-known that this basic assumption is flawed (e.g. Marsalek, 1978; Wenzel and Voorhees, 1978, 1979; Wenzel, 1982; Robinson and James, 1984; Adams and Howard, 1986).

An alternative approach which overcomes the shortcomings of the design storm approach is continuous simulation. This involves the use of long-term historical precipitation records together with a simulation model to evaluate the simulated historical response of a proposed system. The design is modified so as to produce an acceptable statistical performance of the system, consistent with the specified continuous probability criteria for flood control. Given a record of sufficient length and an adequate simulation model, the statistics of the continuous simulation model output, and hence the statistics of the system performance, are deemed to be reliable. The disadvantage of the continuous simulation approach is that it may be costly and awkward because of the data assembly and analysis efforts required. As a result, continuous simulation has not been commonly used in sizing flood control detention facilities. 
Analytical procedures were developed to approximate the continuous simulation modeling approach for the sizing of detention facilities for flood control purposes (Guo, 1998). With a triangular inflow hydrograph and the assumptions that at the start of any runoff event, the detention facility is empty, and that the outflow hydrographs have a linear rising limb, the routing of the hydrograph through a detention facility for each runoff event is represented in Figure 19.1.

As shown in Figure 19.1, the time base of the inflow hydrograph is $t+t_{c}$, where $t$ is the duration of the causal rainfall event and $t_{c}$ is the catchment time of concentration. The outflow occurs immediately after the start of the inflow hydrograph. The outflow hydrograph intersects the inflow hydrograph at the peak of the outflow hydrograph along the recession limb of the inflow hydrograph, since the detention volume is specifically designed to avoid uncontrolled spills. The volume of the runoff event, $\mathrm{v}_{\mathrm{r}}$, in mm of water over the catchment, entering the detention facility is equal to the area enclosed by the inflow hydrograph. The shaded area in Figure 19.1, denoted $\mathrm{S}_{\mathrm{Q}_{0}}$, is equal to the maximum storage volume utilized during the passage of the runoff event. Hence, the peak outflow rate, $Q_{0}$, is the discharge rate of the detention facility at storage volume $S_{Q_{g}}$.

From Figure 19.1, it can be seen that:

$$
\mathrm{S}_{\mathrm{Q}_{\mathrm{o}}}=\frac{1}{2}\left(\mathrm{Q}_{\mathrm{i}}-\mathrm{Q}_{\mathrm{o}}\right)\left(\mathrm{t}+\mathrm{t}_{\mathrm{c}}\right)
$$

where $Q_{i}$ is the peak inflow rate. $Q_{i}$ and $Q_{0}$ are both in the units of $m m / h, S_{Q_{0}}$ is in units of $\mathrm{mm}$, and $t$ and $t_{c}$ are both in $h$. Rearranging Equation 19.9, and noting that

$$
v_{r}=\frac{1}{2} Q_{i}\left(t+t_{c}\right)
$$

the following is obtained:

$$
\mathrm{Q}_{0}=\frac{2\left(\mathrm{v}_{\mathrm{r}}-\mathrm{S}_{\mathrm{Q}_{0}}\right)}{\mathrm{t}+\mathrm{t}_{\mathrm{c}}}
$$

The storage-discharge relationship of a detention facility is described by a table of ordered pairs of storage volume and discharge rate values. Each pair of these values is denoted $\left(S_{q}, q\right)$, where $S_{q}$ is the storage volume of the detention facility at which the routed discharge rate from the facility equals the given value q. Utilizing the functional relationship between dependent random variable $Q_{0}$ and independent random variables $v_{r}$ and $t$ as described in Equation 19.10, Guo (1998) derived an analytical expression for the exceedance probability $P\left[Q_{0}>q\right]$ as a function of contributing catchment hydrologic parameters, meteorological parameters, and $q$ and the corresponding $\mathrm{S}_{\mathrm{q}}$ values. The ordered combinations of $P\left[Q_{0}>q\right]$ for all the possible discrete values of $q$, that are of interest in planning 
and design, form the probability distribution of the peak outflow rate $Q_{0}$. Using this derived probability distribution, the return periods of routed peak discharge rates $\mathrm{q}$ from a detention facility servicing an urban catchment can be analytically determined. The details of the derivation process and the final analytical expressions can be found in Guo (1998).

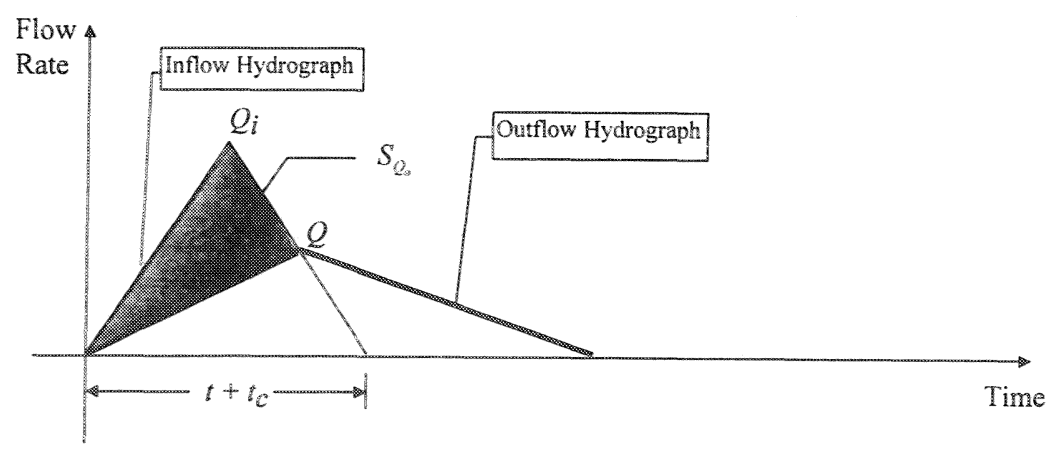

Figure 19.1 Routing of hydrographs through detention ponds.

\subsection{Verification of ASWMM}

The closed-form mathematical expressions discussed in the preceding sections, collectively referred to as ASWMM, provide a facile and efficient means to evaluate the average annual runoff volume, return periods of runoff event volumes and peak discharge rates from an urban catchment, and the performance of stormwater quality and flood control ponds. Continuous hydrologic simulation using long-term historical rainfall records can provide similar information, although with a much greater effort. To test the assumptions made in the development of ASWMM, continuous SWMM simulation runs were performed for catchments with different levels of imperviousness and various soil types, and detention ponds with various configurations, for comparative purposes. The 33year historical rainfall record of the Pearson International Airport in Toronto was used as the rainfall input to the continuous simulation runs. For each year, the rainfall data contain precipitation records for the rainfall year (March through November) only. A sample of these comparative results is presented below. Details of the catchment and pond configurations and more comparative results can be found in Guo (1998). 


\subsubsection{Average Annual Runoff Volume}

The average annual runoff volumes determined from continuous SWMM simulations are compared with those from ASWMM. The average annual rainfall volume determined from the 33-year rainfall record of the Pearson International Airport in Toronto is approximately $550 \mathrm{~mm}$. Table 19.2 presents the input parameter values for the ASWMM and comparison of results. The values of the input parameters in Table 19.2 are the corresponding SWMM input parameter values or are estimated from SWMM input parameter values.

Table 19.2 Comparison of ASWMM and SWMM results on average annual runoff volume.

\begin{tabular}{ccccc|cc|c}
\hline \multicolumn{5}{c|}{ Input Parameter Values } & \multicolumn{2}{|c|}{$\begin{array}{c}\text { Average Annual } \\
\text { Runof Volume }\end{array}$} & $\begin{array}{c}\text { Relative } \\
\text { Difference }\end{array}$ \\
\cline { 1 - 4 } & $\begin{array}{c}\mathrm{S}_{\mathrm{di}} \\
(\mathrm{mm})\end{array}$ & $\begin{array}{c}\mathrm{S}_{\mathrm{dp}} \\
(\mathrm{mm})\end{array}$ & $\begin{array}{c}\mathrm{S}_{\mathrm{iw}} \\
(\mathrm{mm})\end{array}$ & $\begin{array}{c}\mathrm{F}_{\mathrm{c}} \\
(\mathrm{mm} / \mathrm{hr})\end{array}$ & $\begin{array}{c}\text { SWMM } \\
(\mathrm{mm})\end{array}$ & $\begin{array}{c}\text { Analytical } \\
(\mathrm{mm})\end{array}$ & \\
\hline 0.2 & 1.5 & 4.5 & 4.0 & 0.36 & 223 & 227 & $2 \%$ \\
0.2 & 1.5 & 4.5 & 13.2 & 3.6 & 115 & 109 & $-5 \%$ \\
0.2 & 1.5 & 4.5 & 17.3 & 36 & 102 & 93 & $-8 \%$ \\
0.45 & 1.5 & 4.5 & 4.0 & 0.36 & 307 & 300 & $-2 \%$ \\
0.45 & 1.5 & 4.5 & 13.2 & 3.6 & 232 & 218 & $-6 \%$ \\
0.45 & 1.5 & 4.5 & 17.3 & 36 & 222 & 208 & $-7 \%$ \\
0.7 & 1.5 & 4.5 & 4.0 & 0.36 & 389 & 373 & $-4 \%$ \\
0.7 & 1.5 & 4.5 & 13.2 & 3.6 & 348 & 328 & $-6 \%$ \\
0.7 & 1.5 & 4.5 & 17.3 & 36 & 343 & 322 & $-6 \%$ \\
1 & 1.5 & 4.5 & & & 487 & 460 & $-6 \%$ \\
\hline
\end{tabular}

Table 19.2 shows that the relative differences are all less than $10 \%$. The close agreement on average annual runoff volume indicates that the event based catchment rainfall-runoff transformation utilized for the development of ASWMM closely approximates the time step based rainfall-runoff transformation employed in SWMM, and that the assumptions made in establishing the event based rainfall-runoff transformation are acceptable, practically speaking.

\subsubsection{Runoff Event Volume Return Period}

The runoff event series derived from the continuous SWMM simulations is sorted and ranked in descending order of magnitude of runoff event volume to calculate runoff event volume exceedance probabilities. The exceedance probability is equated to the Weibull plotting position as follows: 
where:

$$
\mathrm{PP}=\frac{\mathrm{M}}{\mathrm{N}+1}
$$

$$
\begin{aligned}
\mathrm{PP}= & \text { the Weibull plotting position of the runoff event; } \\
\mathrm{M}= & \text { the rank of the runoff event according to a descending } \\
& \text { series of runoff event volumes; and } \\
\mathrm{N}= & \text { the total number of rainfall events contained in the } \\
& \text { historical rainfall series input to the SWMM model. }
\end{aligned}
$$

Use of the total number of input rainfall events for $N$ ensures that the runoff event series analyzed include those events with zero runoff volume, so that the plotting position PP is equivalent to the runoff event volume exceedance probability per rainfall event. The annual exceedance probability is simply the product of the exceedance probability per rainfall event and the annual average number of rainfall events.

The SWMM simulated runoff event volume return periods for one of the test catchments are compared in Figure 19.2 with those determined from ASWMM. Similar comparisons are obtained for the other test catchments presented in Guo (1998). The close agreement of runoff event volume return periods demonstrates that ASWMM for runoff volume derived from the event-based rainfall-runoff transformation and the fitted exponential distributions of rainfall event characteristics can generate results comparable to those from continuous SWMM simulations. It also indicates again that the assumptions made in developing the event-based rainfall-runoff transformation equations are acceptable in a practical sense.

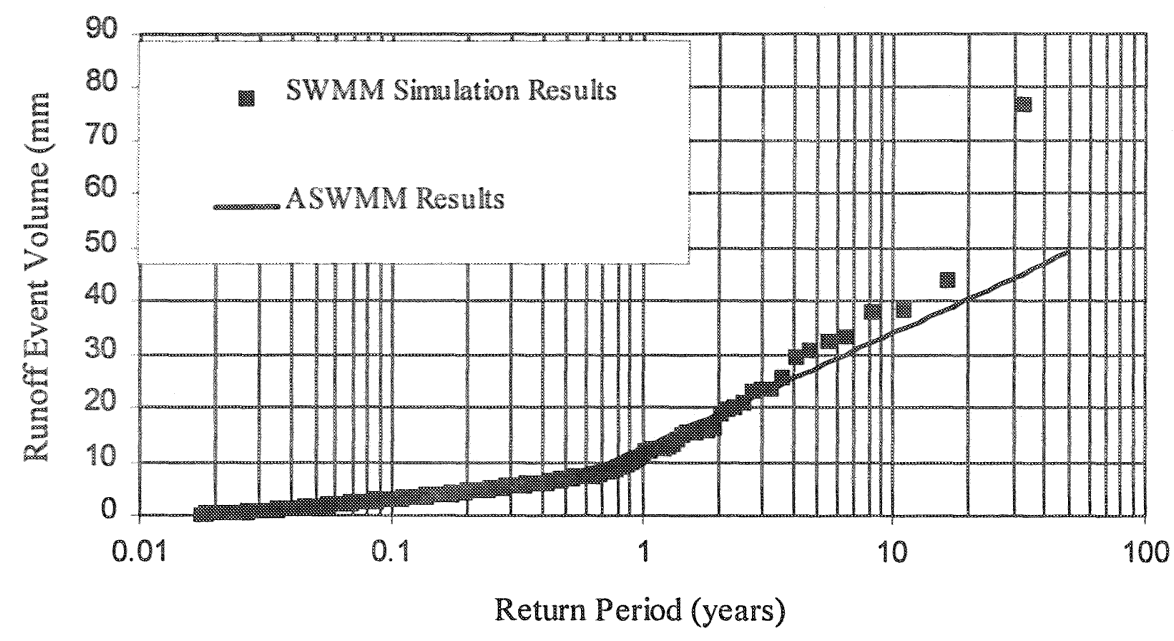

Figure 19.2 Comparison of ASWMM and SWMM results on runoff event volume return period. 


\subsubsection{Peak Discharge Rate Return Period}

Estimates of peak discharge rates associated with return periods greater than one year are often sought in stormwater management analyses. Therefore, a comparison between ASWMM and SWMM results was conducted focusing on only peak discharge rates with return periods greater than one year.

In the statistical analysis of stream discharge data, the annual maximum series (AMS), rather than the complete peak discharge series or peak over a threshold (POT) series, is more commonly used to determine flood frequencies (Chow et al., 1988; Watt et al., 1989). The annual maximum series consists of the maximum discharge rate in each calendar year in the stream discharge record. In general, complete peak discharge series or POT series result in higher flood peak predictions for lower return periods than the AMS. For larger return periods (the upper end of the return period-discharge curve), the three different series often yield similar results. The determination of peak discharge rate return period from peak discharge exceedance probability per rainfall event is equivalent to the use of a complete peak discharge series in a frequency analysis. Thus, the analytically calculated peak discharge rates are generally expected to be somewhat larger, for return periods of the order of one to two years, than those determined from annual maximum series. Nevertheless, due to the general popularity of AMS, the analytically calculated peak discharge rate return periods are compared with those obtained from AMS derived from continuous SWMM simulation results.

Figure 19.3 shows the comparison of peak discharge rate return periods for one of the test catchments discussed in Guo (1998). The plotting positions of the SWMM simulated AMS in the Figure 19.3 are obtained by ranking the AMS and equating the Weibull plotting position to the annual exceedance probability.

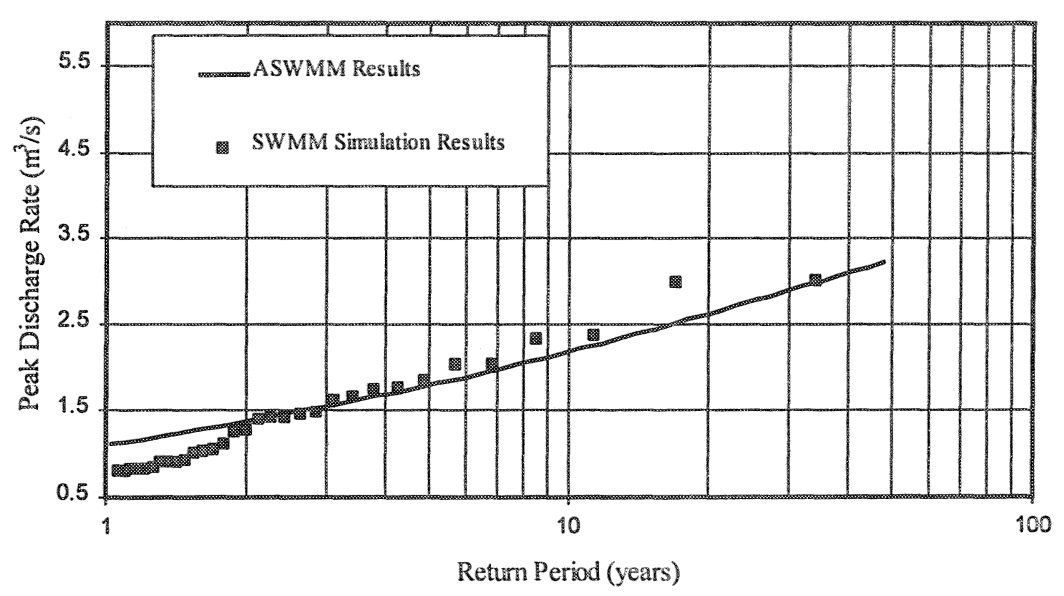

Figure 19.3 Comparison of ASWMM and SWMM results on peak discharge rate return period. 
The $t_{c}$ values required for input to the ASWMM are estimated using kinematic wave theory in accordance with a procedure outlined in Guo (1998). In practical applications, observed single event rainfall-runoff data may be used to estimate $t_{c}$. This estimated $t_{c}$ can then be used as input to ASWMM. The process of estimating $t_{c}$ for analytical models is equivalent to the calibration of numerical hydrological models by adjusting values of parameters such as slope, roughness and width of the catchment to match observed runoff hydrographs.

\subsubsection{Flow Capture Efficiency}

The Storage/Treatment Block of SWMM was used to simulate the different pond configurations. The output of the SWMM model contains summary information on total inflow to the pond, total bypass, and total treated outflow. These summary data are used to calculate the long-term average flow capture efficiencies.

The ASWMM and SWMM simulation results are compared in Figure 19.4 for two storage levels. Similar comparisons were obtained for other storage levels (Guo, 1998). These comparisons indicate that for the practical range of storage volumes, the analytical flow capture efficiencies agree well with those determined from SWMM simulations.

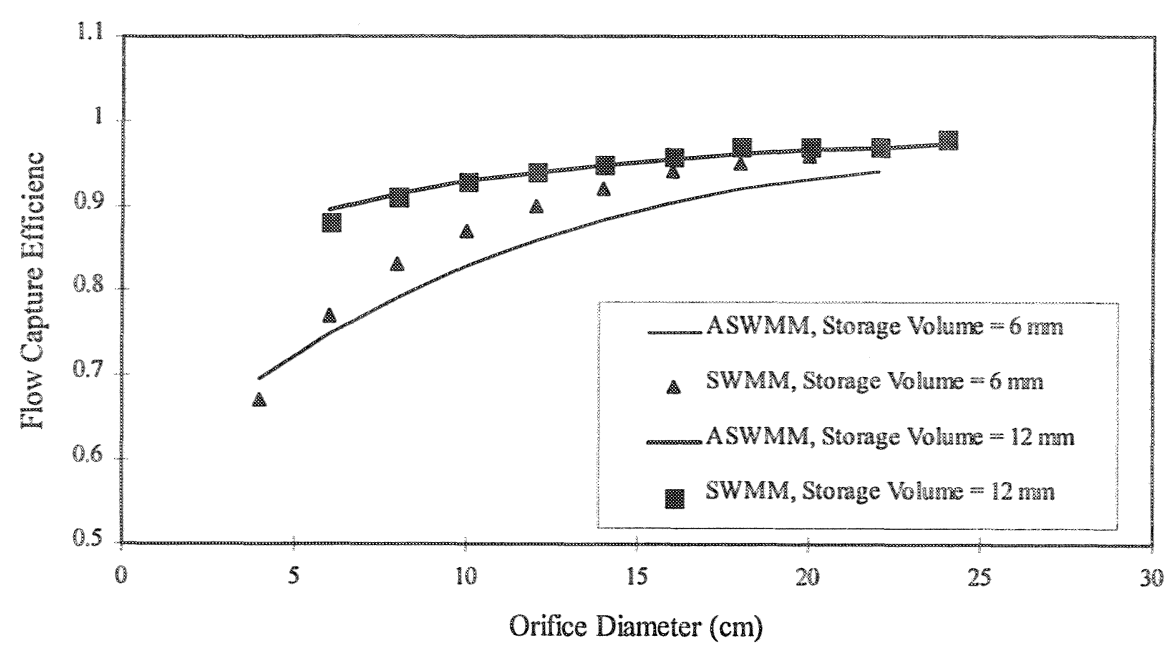

Figure 19.4 Comparison of ASWMM and SWMM results on flow capture efficiency. 


\subsubsection{Average Detention Time}

SWMM does not explicitly output detention times for individual runoff events routed through a pond, nor does it output average detention time of a pond in longterm continuous simulation mode. However, the inflow and outflow series from a long-term continuous simulation can both be separated into discrete events based on a minimum interevent time definition and a minimum threshold flow value. The time bases of the individual inflow and outflow events can subsequently be determined. For an individual runoff event, the volume-weighted detention time is the distance between the centroids of the inflow and outflow hydrographs, which can be approximated by half of the difference between the time bases of the outflow and inflow hydrographs. In cases where the pond is not empty when a new event starts, the time base of the outflow hydrograph terminates at the time the new event begins.

Obviously, the volume-weighted detention time for individual events calculated using the above procedure from SWMM simulation results will vary from event to event. However, an average volume-weighted detention time per runoff event can be estimated by averaging the detention times of all the events within the simulation period. This average volume-weighted detention time can be determined by calculating the total durations of the inflow and outflow events. The total duration of outflow events from the pond, and the total duration of inflow events to the pond are the sums of the time bases of the outflow and inflow events, respectively. The average detention time per runoff event can then be calculated as half of the difference between the total outflow and inflow durations divided by the total number of inflow runoff events. In distinguishing runoff events, an IETD was used for the inflow series, since a $6 \mathrm{hr}$. IETD was used for separating rainfall events. The IETD for the outflow series is less critical since it does not affect the total duration of outflow events. A minimum threshold flow value of $10^{-5} \mathrm{~m}^{3} / \mathrm{s}$ was used for both the inflow and outflow series.

Comparisons of ASWMM and SWMM results on average detention time for two sets of pond configurations are presented in Figure 19.5. More comparisons can be found in Guo (1998). As shown in Figure 19.5, the analytical results are in close agreement with those determined from SWMM simulations for the ranges of storage volumes and detention times analyzed.

\subsubsection{Peak Outflow Rate Return Period}

The comparison between the return period curves of peak outflow (from a flood control detention pond servicing an urban catchment) determined from ASWMM and from continuous SWMM is presented in Figure 19.6. For this comparison, a desired flood frequency curve was first chosen by selecting discharge rate values for each return period (i.e. $50 \%$ reduction from those under uncontrolled 


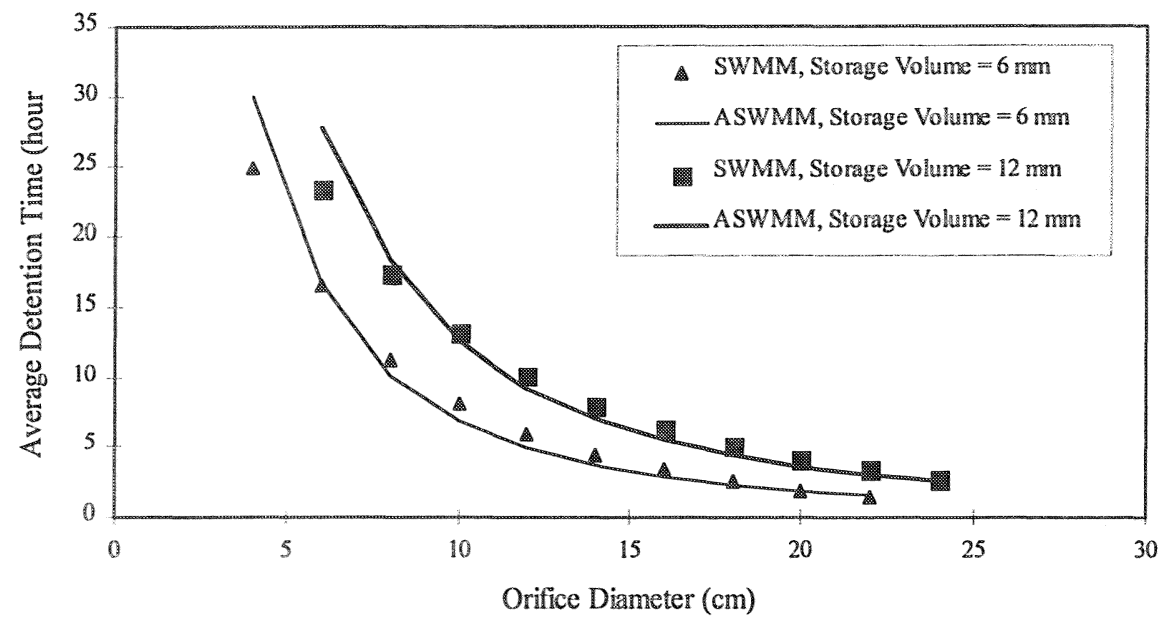

Figure 19.5 Comparison of ASWMM and SWMM results on average detention time.

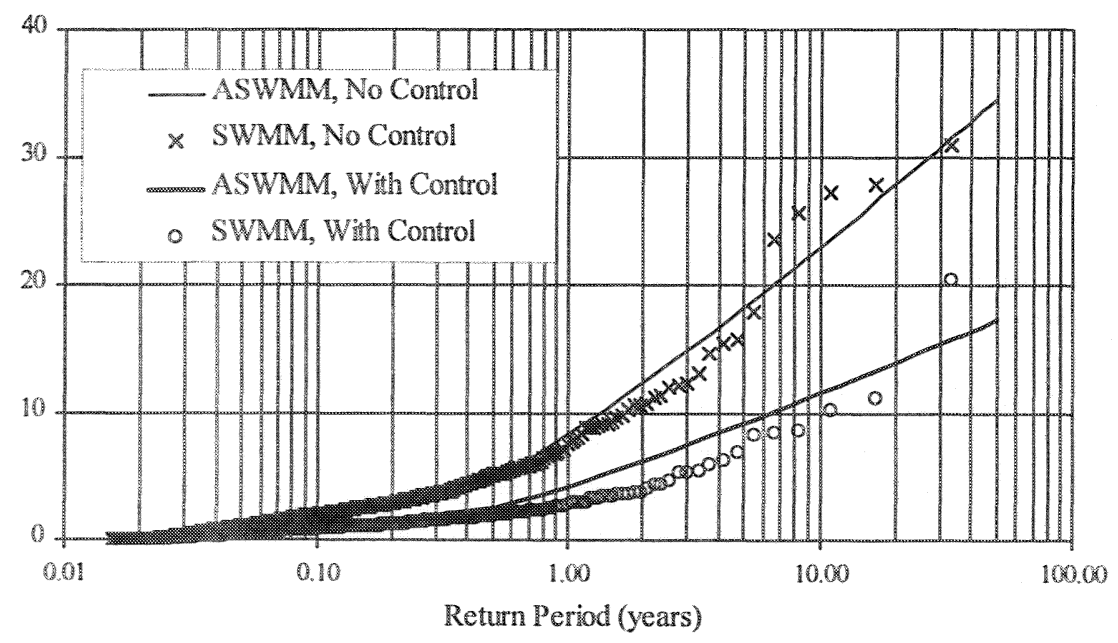

Figure 19.6 Comparison of ASWMM and SWMM results on routed peak outflow rate return period.

conditions). The storage volume required to achieve the peak discharge rate reduction for a specified return period was determined by using ASWMM first. The storage-discharge table required to achieve the selected level of flood control (i.e. to yield the desired flood frequency curve) was constructed from these 
storage volumes and peak discharge rates in the order of increasing return period. The storage-discharge table constructed by using ASWMM was then used as input data for the corresponding SWMM model.

In Figure 19.6, the analytical flood frequency curve and data points from simulation results when there is no flood control in place for the test catchment are also included. It is shown in Figure 19.6 that the ASWMM curves agree quite well with SWMM simulation results. More comparisons are presented in Guo (1998). These comparisons demonstrate that ASWMM reasonably approximates the continuous simulation results on the flood control performance of detention facilities.

\subsection{Application of ASWMM}

Except for Equations 19.3 and 19.8, the other ASWMM expressions which are not included in this chapter are lengthy and not suitable for hand calculations. Instead, the analytical expressions can be easily coded into a computer spreadsheet. Given that statistical analysis of long-term historical rainfall data is performed a priori, with such a spreadsheet, the runoff event volume return period, peak discharge rate return period, and the performance of stormwater quality and flood control detention ponds can be evaluated with relative ease. For planning and design purposes, it is convenient to directly solve for runoff event volume or peak discharge rate with a specified return period, as well as the storage volume required to achieve a specified performance level. However, most of the analytical expressions are transcendental equations and some of them cannot be reduced to algebraic equations. Explicit analytical expressions for the peak discharge rate of a certain return period or the required storage volume for achieving certain level of performance cannot be derived. But these unknowns can be efficiently determined in a computer spreadsheet by trial-and-error.

Figure 19.7 is a sample spreadsheet for the application of ASWMM for flood control analyses. The upper half of the spreadsheet is for the input of meteorological and hydrological parameters, while the lower half is for calculation and plotting of the results. The meteorological parameter values for a given location are determined a priori by statistical analysis of the long-term rainfall record of the location. In the lower half of the spreadsheet, the first two columns are simply the storage-discharge table of the detention facility. The third column is the return period of the peak discharge rate equaling the discharge rate of the detention facility with the installation of the flood control detention facility. The third column is thus a formula column incorporating the corresponding ASWMM expressions. The graph to the right of the three columns is the plot of Column 2 versus Column 3. 


\section{Flood Control Detention Facility Sizing Procedure}

\begin{tabular}{cccll}
\hline & & \multicolumn{3}{c}{ Localmeteorological Parameters } \\
$\zeta$ & $=0.1061$ & $1 / \mathrm{mm}$ & (The inverse of the mean rainfall event volume.) \\
$\lambda=$ & 0.1294 & $1 / \mathrm{h}$ & (The inverse of the mean rainfall event duration.) \\
$\theta$ & $=57.2$ & events & (The average number of rainfall events per year.) \\
\hline
\end{tabular}

\section{Catchment Hydrological Parameters}

User Input Parameters

Catchment Area, $A=$

200 hectares

Fraction of Impervious Areas, $h=$

0.35

Impervious Area Depression Storage, $S_{d i}=$

$1.5 \mathrm{~mm}$

Pervious Area Depression Storage, $S_{d p}=$

$4.5 \mathrm{~mm}$

Pervious Area Ultimate Infiltration Capacity, $f_{c}=$

$3.6 \mathrm{~mm} / \mathrm{h}$

Pervious Area Initial Soil Wetting Infiltration, $S_{i w}=$

$13.2 \mathrm{~mm}$

Catchment Time of Concentration, $t_{c}=$

2.1 hours

\section{Calculated Parameters}

Pervious Area Initial Losses, $S_{i l}=S_{d p}+S_{i w}=$

$17.7 \mathrm{~mm}$

Area-Weighted Catchment Initial Losses, $S_{d}=h S_{d i}+(1-h) S_{i l}=$

$12.03 \mathrm{~mm}$

The Difference Between Pervious and Impervious Area

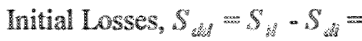

$16.2 \mathrm{~mm}$

Calculations Using the Analytical Probabilistic Models

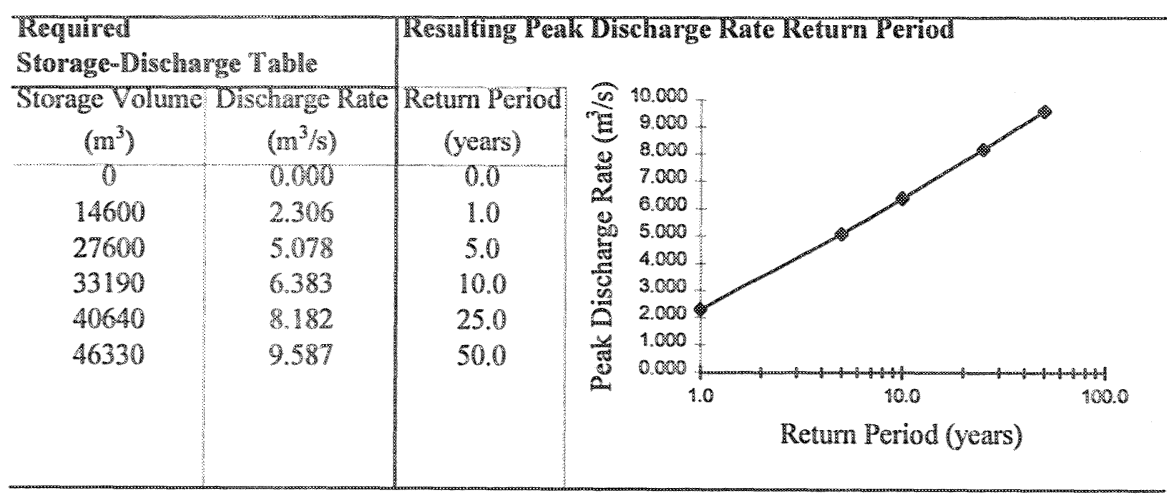

Figure 19.7 Sample spreadsheet implementation of ASWMM.

The above spreadsheet can be used to determine the flood control effectiveness of a given design. This is performed by simply inputting the storagedischarge relationship of the detention facility into Columns 1 and 2 in the lower half of the spreadsheet, and the related catchment and meteorological data in the upper half of the spreadsheet. The return periods in Column 3 in the lower half of the spreadsheet are then automatically calculated, and the plot of peak 
discharge rate versus return period is automatically generated. The results can be examined to determine if the intended flood control objective is satisfied.

In planning and design situations, the catchment hydrologic parameters are input to the upper half of the spreadsheet first. If the design criterion is specified in the form of controlling peak discharges of a series of return periods at certain levels (as is usually the case for most jurisdictions throughout North America), the series of discharges of specified return periods are input to Column 2 first, the required storage volumes to yield the desired return periods are determined by trial-and-error in Column 1 (i.e. different storage volumes in Column 1 are tried until the desired return period in Column 3 is obtained).

\subsection{Conclusions}

The exponential pdfs of rainfall event characteristics, tested and accepted in previous research for various locations, are used in this research as the starting point for the derivation of the analytical expressions constituting ASWMM. The close agreement between ASWMM and SWMM results indicates that the eventbased rainfall-runoff transformation generates runoff volumes comparable with those from time-step based rainfall-runoff transformations used in many numerical hydrologic models. Furthermore, the close agreement of results illustrates that the exponential distributions used for rainfall event characteristics and the assumptions invoked for the simplification of the mathematical representation of catchment runoff routing and detention pond flow routing are acceptable in practice.

Implemented in computer spreadsheets, ASWMM can be used very efficiently for the determination of the probability distribution of runoff event volume and peak discharge rate from urban catchments, as well as for the determination of the performance of stormwater quality and flood control detention ponds servicing urban catchments. More complete discussions of the development, implementation, and limitations of ASWMM can be found in Guo (1998).

\section{Notation}

a slope of the storage-discharge curve of a detention pond, $h$.

b interevent time, $h$.

$\vec{b}$ the mean interevent time of a long-term rainfall record, $h$.

$\mathrm{C}_{\mathrm{R}} \quad$ flow capture efficiency.

$\mathrm{E}(\bullet)$ expected value of $(\cdot)$. 
$f_{c} \quad$ ultimate infiltration capacity of a soil, $\mathrm{mm} / \mathrm{h}$.

$f_{B}$ (b) probability density function of random variable $b$.

$f_{T}(t)$ probability density function of random variable $t$.

$f_{\mathrm{V}}(v)$ probability density function of random variable $v$.

$h$ fraction of impervious areas of an urban catchment.

$M \quad$ rank of an event in a descending series of events.

$N \quad$ total number of rainfall events in a given period.

$P \quad$ total spill volume, $\mathrm{mm}$.

PP plotting position.

$\mathrm{P}_{\mathrm{c}} \quad$ carryover spill volume, $\mathrm{mm}$.

$\mathrm{P}_{\mathrm{e}} \quad$ event spill volume, $\mathrm{mm}$.

$\mathrm{q}$ a given peak discharge rate, $\mathrm{mm} / \mathrm{h}$ or $\mathrm{m}^{3} / \mathrm{s}$.

$\mathrm{Q}_{\mathrm{i}} \quad$ peak inflow rate to a flood control detention facility resulting from a runoff event, $\mathrm{mm} / \mathrm{h}$.

$Q_{0} \quad$ peak outflow rate from a flood control detention facility result ing from a runoff event, $\mathrm{mm} / \mathrm{h}$.

$Q_{p} \quad$ peak discharge rate of a runoff event, $\mathrm{mm} / \mathrm{h}$ or $\mathrm{m}^{3} / \mathrm{s}$.

$\mathrm{S}_{\mathrm{d}} \quad$ area-weighted average depression storage of a catchment, $\mathrm{mm}$.

$\mathrm{S}_{\mathrm{di}}$ depression storage of the impervious areas of an urban catch ment, $\mathrm{mm}$.

$S_{d d} \quad$ the difference between the depression storage values of the pervious and impervious areas of an urban catchment, mm.

$\mathrm{S}_{\mathrm{dp}}$ depression storage of the pervious areas of an urban catchment, mm.

$\mathrm{S}_{\mathrm{il}} \quad$ initial losses of the pervious areas of an urban catchment, including $\mathrm{S}_{\mathrm{iw}}$ and $\mathrm{S}_{\mathrm{dp}}, \mathrm{mm}$.

$\mathrm{S}_{\mathrm{iw}} \quad$ initial soil wetting infiltration volume, $\mathrm{mm}$.

$\mathrm{S}_{\mathrm{mf}}$

maximum possible infiltration loss volume during a rainfall event, $\mathrm{mm}$.

$\mathrm{S}_{\mathrm{Q}} \quad$ storage volume utilized when a detention pond is discharging at a rate of $Q, \mathrm{~mm}$.

$t$ rainfall event duration, $h$.

$\vec{t}$ the mean of rainfall event duration of all rainfall events con tained in a long-term rainfall record, $h$.

$t_{c} \quad$ catchment time of concentration, $h$.

$\mathrm{v}$ rainfall event volume, $\mathrm{mm}$.

$\bar{v} \quad$ the mean of rainfall event volume of all rainfall events con tained in a long-term rainfall record, $\mathrm{mm}$.

$\mathrm{v}_{\mathrm{r}} \quad$ runoff event volume, $\mathrm{mm}$.

$\lambda$ parameter in the probability density function for rainfall event duration $\mathrm{t}, \mathrm{h}^{-1}$

$\theta \quad$ average annual number of rainfall events. 

b, $h^{-1}$

$\zeta \quad$ parameter in the probability density function for rainfall event volume $\mathrm{v}, \mathrm{mm}^{-1}$

\section{References}

Adams, B. J., and J. B. Bontje,1984. Microcomputer applications of analytical models for urban stormwater management, in Emerging Computer Techniques in Stormwater and Flood Management, W. James (ed.), ASCE, New York, N. Y., 138-162.

Adams, B. J., H. G. Fraser, C. D. D. Howard, and M. S. Hanafy, 1986. Meteorologic data analysis for drainage system design, Journal of Enviromental Engineering, ASCE, Vol. 112, No. 5, 827-848.

Adams, B. J., and C. D. D. Howard,1986. Design storm pathology, Canadian Water Resources Journal, Vol. 11, No. 3, 49-55, Canadian Water Resources Association.

Benjamin, J. R., and C. A. Cornell, 1970. Probability, Statistics and Decision for Civil Engineers, McGraw-Hill, New York.

Chow, V. T., D. R. Maidment, and L. W. Mays, 1988. Applied Hydrology, McGraw-Hill Book Company, New York, New York, 1988.

Eagleson, P. S., Dynamics of flood frequency, 1972. Water Resources Research, Vol. 8 , No. 4, 878-897.

Fraser, H. G., 1982. Frequency of Storm Characteristics: Analysis and Implications for Volume Design, M.A.Sc. thesis, Department of Civil Engineering, University of Toronto, Toronto, Ontario.

Guo, Y., 1988. Development of Analytical Probabilistic Urban Stormwater Models, Ph.D. thesis, Department of Civil Engineering, University of Toronto, Toronto, Ontario.

Howard, C. D. D., 1976. Theory of storage and treatment plant overflows, Journal of Environmental Engineering, ASCE, Vol. 102, No. EE4, 709-722.

Huber, W. C., and R. E. Dickinson, 1988. Stormwater Management Model, Version 4: User's Manual, Environmental Research Laboratory, Office of Research and Development, U. S. Environmental Protection Agency, Athens, Georgia, August, 1988.

Marsalek, J.,1978. Research on the design storm concept, Tech. Memo. 33, ASCE, Urban Water Resources Research Program, New York.

Restrepo-Posada, P. J., and P. S. Eagleson, 1982. Identification of independent rainstorms, Journal of Hydrology, Vol. 55, 303-319.

Robinson, M. and W. James, 1984. Continuous variable resolution stormwater modelling on a microcomputer, Proceedings, Conference on Stormwater and Water Quality Management Modeling, September 1984, Burlington, Ontario, E. M. and W. James (eds.), McMaster University, 59-73.

Walesh, S. G., 1989.Urban Surface Water Management, John Wiley \& Sons, Inc., New York.

Watt, W.E., etal. 1989. Hydrology of Floods in Canada: A Guide to Planning and Design, National Research Council of Canada, Ottawa, Ontario. 
Wenzel, H. G., Jr., 1982. Rainfall for urban stormwater design, in Urban Stormwater Hydrology, Water Resources Monograph 7, D. F. Kibler(ed.), American Geophysical Union, Washington, D. C.

Wenzel, H. G., Jr., and M. L. Voorhees, 1978. Evaluation of the design storm concept, paper presented at the American Geophysical Union Annual Fall Meeting, San Francisco, California, December 1978.

Wenzel, H. G., Jr., and M.L. Voorhees, 1979. Sensitivity of design storm frequency, paper presented at the American Geophysical Union Annual Spring Meeting, Washington, D. C., May 1979. 


i

